\title{
Monitoreo de la tasa de error de modulación de la señal digital de televisión
}

\author{
Fecha de recepción: 15/11/2019 • Fecha de aceptación: 10/01/2020 • Fecha de publicación:10/02/2020
}

Nancy Rodriguez

Organización Ecuatoriana de Televisión ORTEL S.A

nancyrodriguez@tvc.com.ec

https://orcid.org/0000-0001-6281-442X

\section{RESUMEN}

El servicio de televisión terrestre que se utiliza en Ecuador es en formato analógico NTSC (National Television System Comittee), pero las cadenas televisivas y de radiodifusión están realizando los cambios necesarios para la generación y envió de la señal digital a los usuarios debido al apagón analógico que esta por realizarse en los siguientes años y así poder dar paso a la televisión digital y optimizar los servicios como la calidad del audio y video, tener una guía de programación, poder receptar la señal de televisión en dispositivos móviles. En el canal de televisión Televicentro se necesita analizar la generación de la señal digital para realizar el monitoreo de la tasa de error de la modulación y poder saber en qué lugares se debe medir la tasa de error de modulación para comparar los valores y verificar la calidad de la señal. En la ciudad de Quito no se ha realizado el análisis de la generación de la señal digital del canal Televicentro, porque el canal es relativamente nuevo lleva al aire más de dos años y también por políticas de seguridad de la empresa. Se realiza el análisis de la generación de la señal digital radiada en la estación terrena, para realizar mediciones que permitan monitorear la tasa de error de modulación y con esos datos verificar la calidad de dicha señal del canal Televicentro de Quito. La tasa de error de modulación es el parámetro que cuantifica los errores de una constelación digital, este factor facilita valorar si una señal digital es buena; el cálculo de este factor en transmisión lleva implícita la demodulación de la señal para la evaluación. En la recepción, este parámetro se determina tras la demodulación propia de la recepción de los datos. En ambos casos, es necesario el uso de la constelación de transmisión normalizada como referencia; la calidad de la señal que se transmite en la estación terrena del canal Televicentro tuvo un valor promedio 
de $36.554 \mathrm{~dB}$ y de $34.38 \mathrm{~dB}$ en la recepción de la señal digital, respecto al valor mínimo que se debe superar en este caso de $23 \mathrm{~dB}$ y llegando a un valor óptimo de $40 \mathrm{~dB}$.

PALABRAS CLAVE: Televisión, digital, transmisión, recepción, MER

\begin{abstract}
Terrestrial television used in Ecuador is in analog format NTSC (National Television System Committee), but television and broadcasting chains are making the necessary changes to the generation and sent the digital signal to the users due to the analogue switch that is carried out in the following years and so to make way for digital television and optimize the services as the quality of the audio and video, a programming guide, can both receive the signal of TV devices Mobile. In TV channel Televicentro needs to analyze the generation of the digital signal to carry out the monitoring modulation error rate and be able to know where modulation error rate should be measured to compare values and verify the warm (d) of the signal. In the city of Quito not done analysis of the generation of the digital signal of the channel of Televicentro, because the canal is relatively new leads to air over two years and also by the company's security policies. Analysis of the generation of the signal digital radiated at the ground station, to make measurements that allow monitoring the modulation error rate and with that data verify the quality of the signal of the channel Televicentro de Quito. Modulation error rate is the parameter that quantifies a constellation digital errors, this factor makes it easy to assess if a digital signal is good; the calculation of this factor in transmission implies the demodulation of the signal for the evaluation. At the reception, this parameter is determined after the demodulation of the reception of the data. In both cases, it is necessary the use of the constellation of transmission standard as a reference; the quality of the signal that is transmitted in the ground station of the Televicentro canal had an average of $36.554 \mathrm{~dB}$ and 34 . $38 \mathrm{~dB}$ digital signal reception, with respect to the minimum value that must be overcome in this case of $23 \mathrm{~dB}$ and arriving at an optimal value of $40 \mathrm{~dB}$.
\end{abstract}

KEYWORDS: Television, digital, transmission, reception, MER 


\section{INTRODUCCIÓN}

El servicio de televisión terrestre que se utiliza en Ecuador es en formato analógico NTSC (National Television System Comittee), pero las cadenas televisivas y de radiodifusión están realizando los cambios necesarios para la generación y envió de la señal digital a los usuarios debido al apagón analógico que esta por realizarse en los siguientes años y así poder dar paso a la televisión digital y optimizar los servicios como la calidad del audio y video, tener una guía de programación, poder receptar la señal de televisión en dispositivos móviles, etc.

Uno de los cambios necesarios que se realizó fueron los transmisores que en lugar de ser analógicos ahora son digitales, estos transmisores no poseen un sistema que permita verificar si la señal tiene cambios que degraden su calidad antes de ser emitida, este monitoreo es realizado mediante equipos adicionales lo que no permite que sea constante la verificación de la señal. Dichos equipos de monitoreo miden si la señal de televisión posee desvanecimientos o interferencias al medir la tasa de error en la modulación de la señal.

Las características que tiene la señal de televisión al generarla son: forma de onda, ancho de banda, tasa de error de modulación (Modulation Error Rate - MER), tasa de error binario (Bite Error Rate - BER), desviación absoluta de frecuencia y verificación del transport stream, características que son necesarias para la transmisión óptima de la señal digital terrestre de televisión.

En el canal de televisión Televicentro se necesita analizar la generación de la señal digital para realizar el monitoreo de la tasa de error de la modulación y poder saber en qué lugares se debe medir la tasa de error de modulación para comparar los valores y verificar la calidad de la señal.

El objetivo general es analizar la generación de la señal digital radiada en la estación terrena, para realizar mediciones que permitan monitorear la tasa de error de modulación y con esos datos verificar la calidad de dicha señal del canal Televicentro de Quito.

Ya que, en la ciudad de Quito no se ha realizado el análisis de la generación de la señal digital del canal Televicentro, porque el canal es relativamente nuevo lleva al aire más de dos años y también por políticas de seguridad de la empresa, que no permiten el ingreso de cualquier persona al cuarto de quipos. No se tiene manuales o diagramas de la red de la generación de la señal, se está en proceso de realizar los diagramas de bloque de cada una de las áreas del canal.

La validación de la tasa de error de modulación en la señal digital será un aporte tecnológico para el canal de televisión Televicentro, para poder verificar que la calidad de la señal sea óptima, que se está emitiendo la señal sin interferencias, con los estándares permitidos por el Sistema de Televisión Terrestre TDT.

Realizar el monitoreo de la señal de televisión es una tarea obligatoria en el canal Televicentro, porque el objetivo principal de la televisión es contribuir explícita y cotidianamente a la construcción del espacio público en cuanto escenario de comunicación y diálogo entre los diversos actores sociales y las diferentes comunidades culturales. 
El monitoreo se lo realiza en la ciudad de Quito, en el sector de San Bartolo al sur de la ciudad donde se encuentra ubicada las instalaciones del canal Televicentro. Se escogió este canal en específico porque se tiene acceso a todos los equipos que conforman la cabecera de televisión del canal.

La información de la transmisión de la señal digital de un canal de televisión es reservada y restringida, por contener equipos sensibles de un servicio a la comunidad por este motivo este análisis solo se puede realizar en el canal Televicentro.

Al realizar el análisis de los equipos que se utilizan para la generación de la señal de televisión digital, se encontraran los puntos específicos para realizar las medicionjes de la tasa de error de modulación antes del transmisor y después de la recepción de la microonda, antes de emitir a la señal abierta de televisión.

En la generación de la señal se obtiene los valores de las mediciones del error de modulación en la transmisión digital de la señal y en la demodulación de la recepción de la señal del aire, los cuales ayudara a chequear la calidad de la señal que se está transmitiendo a los ciudadanos.

Estos datos se obtienen de las mediciones en dos puntos específicos los cuales son: antes de transmisor en la estación terrena y al receptar la señal y demodular mediante una antena dipolo o casera.

\section{Televisión Digital Terrestre}

La Televisión Digital Terrestre llamada TDT, su nombre se debe al tipo de tecnología que usa para transmitir la señal, también codifica las señales en forma binaria creando un canal de retorno para el usuario; la diferencia entre la señal análoga y la digital es la calidad de video, imagen y audio, la movilidad, la conectividad, entre otros.

El principal objetivo del TDT es mejorar el uso del espectro radioeléctrico al transmitir varios programas de televisión en un mismo canal UHF con ancho de banda de $6 \mathrm{MHz}$. UHF significa Ultra Alta Frecuencia llamado así por sus siglas en inglés Ultra High Frecuency, es una banda del espectro radioeléctrico en el rango de las frecuencias de 300Mhz a 3Ghz. Para las estaciones de televisión y para los usuarios, el mayor beneficio de la TDT gracias a la eficiencia espectral que posee la modulación digital, es el aumento de cobertura en las zonas de sombra y el complemento en las zonas desatendidas que posee la televisión análoga hoy en día.

Los beneficios para el usuario que ofrecerá la TDT son: múltiples programaciones diferentes dentro de un mismo canal como noticiero, deportes, novelas, series, películas, entre otros;etc; recepción de la señal en dispositivos móviles y portátiles;.recepción de alertas de emergencia como por mensajes de catástrofes naturales; contenido interactivo como información de los programas, sus horarios, grabar la programación, etc; interactividad con el usuario como tele compra, voto electrónico, encuestas, concursos, etc; tele -salud; tele-educación; tele-gobierno 
La mayoría de países de Latinoamérica ya están implementando la transmisión de la Televisión Digital Terrestre como se puede observar en la Figura 1.1, pero Argentina, México y Brazil son los países más avanzados en la migración hacia la TDT, uno de sus principales problemas ha sido el incremento en los precios de los equipos profesionales para la producción y emisión de la señal y los equipos receptores para la ciudadanía.

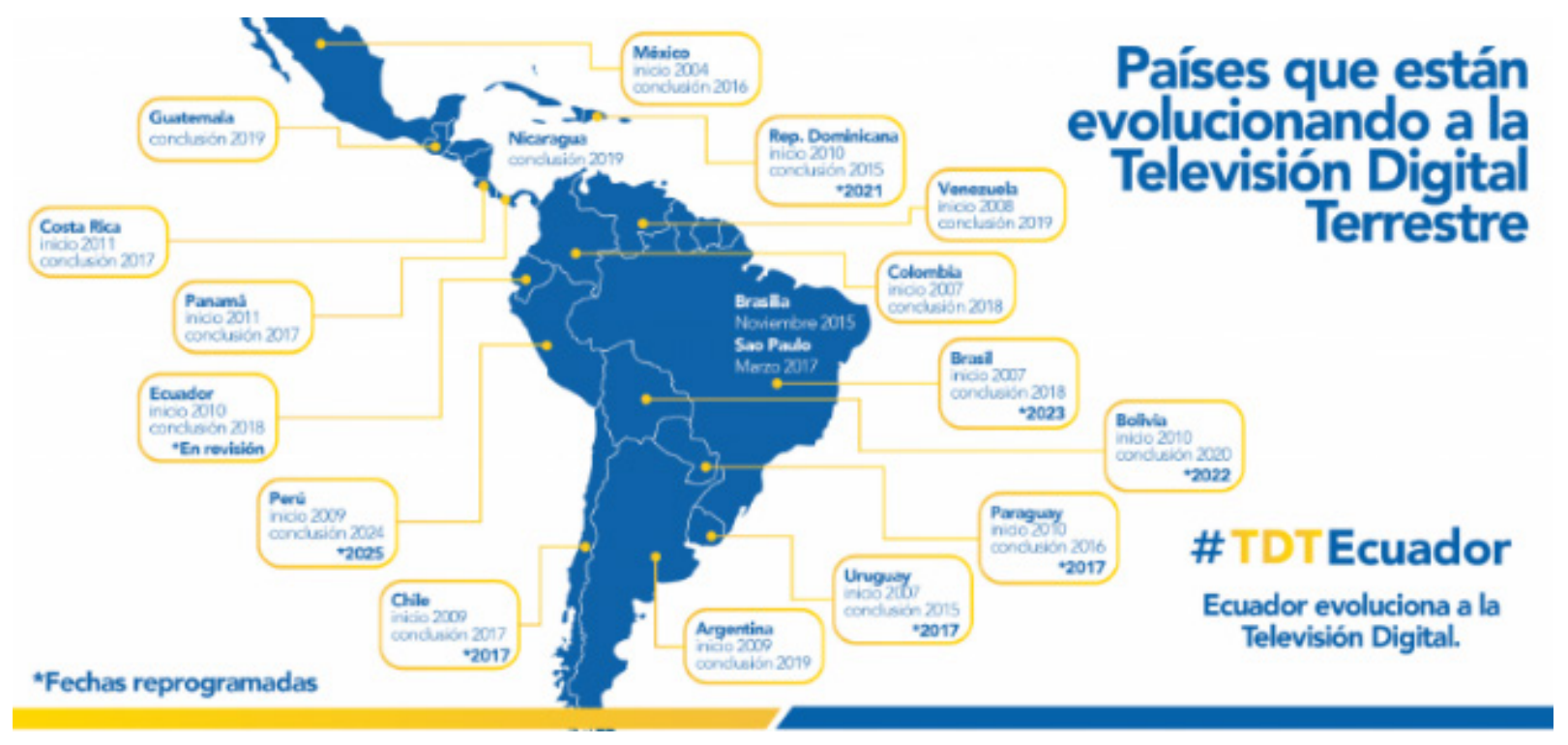

Figura 1.1: Ecuador evoluciona Televisión Digital Terrestre.

El Ecuador desde el 25 de marzo del 2010, utiliza el estándar de televisión digital ISDB-T Radiodifusión Digital Terrestre de Servicios Integrados (Integrated Services Digital Broadcasting - Terrestrial), que es un conjunto de normas para el tratamiento de la señal asegurando la menor pérdida de datos por parte del receptor, creadas en Japón para la transmisión de radio y televisión digital y también se utiliza el estándar ISDB-Tb la b es para indicar las modificaciones que se realizaron en Brasil.

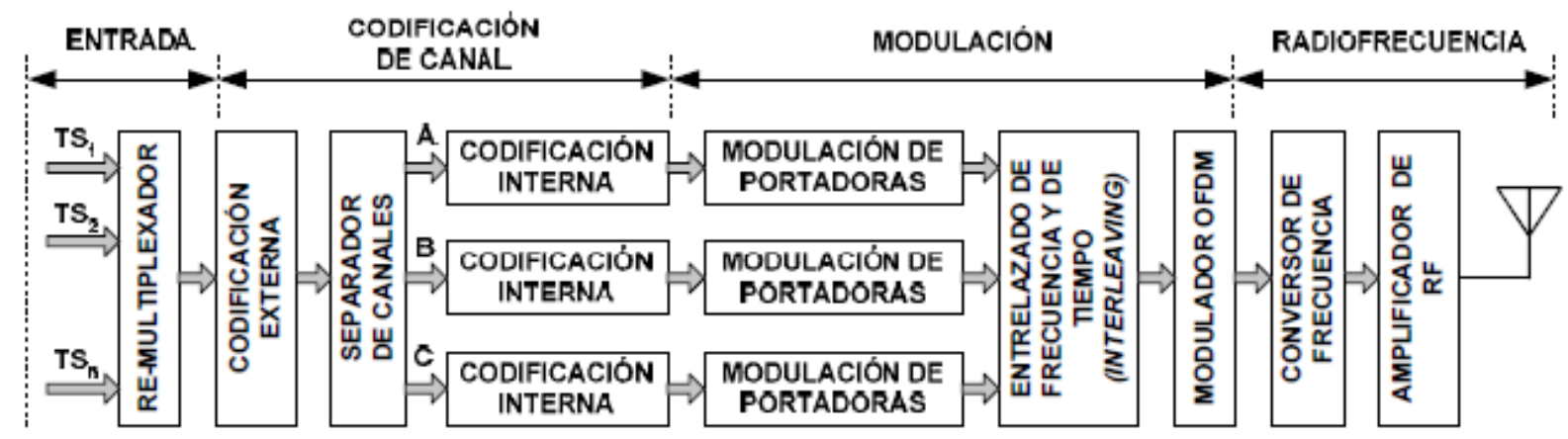

Figura 1.2: Sistema de transmisión ISDB-Tb 
El sistema de transmisión ISDB-Tb como se muestra en la Figura 1.2, posee cuatro grandes bloques de la información de la señal los cuales son: la entrada, la codificación del canal, la modulación y la radiofrecuencia; en la sección de la entrada se puede ver que ingresa toda la corriente de transporte o mejor conocido como Transport Stream - TS de la señal; en la segunda sección se realiza la codificación del canal es donde se añade protección a los datos, se realiza ajustes a los retardos y se divide jerárquicamente la información en tres capas. La tercera sección es la modulación donde se realiza el mapeo de bits es decir es donde se realiza el armado de la constelación I-Q que son los vectores de la información y errores en fase y amplitud; se vuelven a combinar las capas de información entrelazadas en frecuencia y tiempo; en esta sección también se arma el cuadro OFDM que es la multiplexión por división en frecuencias ortogonales, que es el tipo de modulación con la cual se va a enviar la información y la última sección es la radiofrecuencia donde se realiza la conversión de la frecuencia para emitir la señal mediante los transmisores.

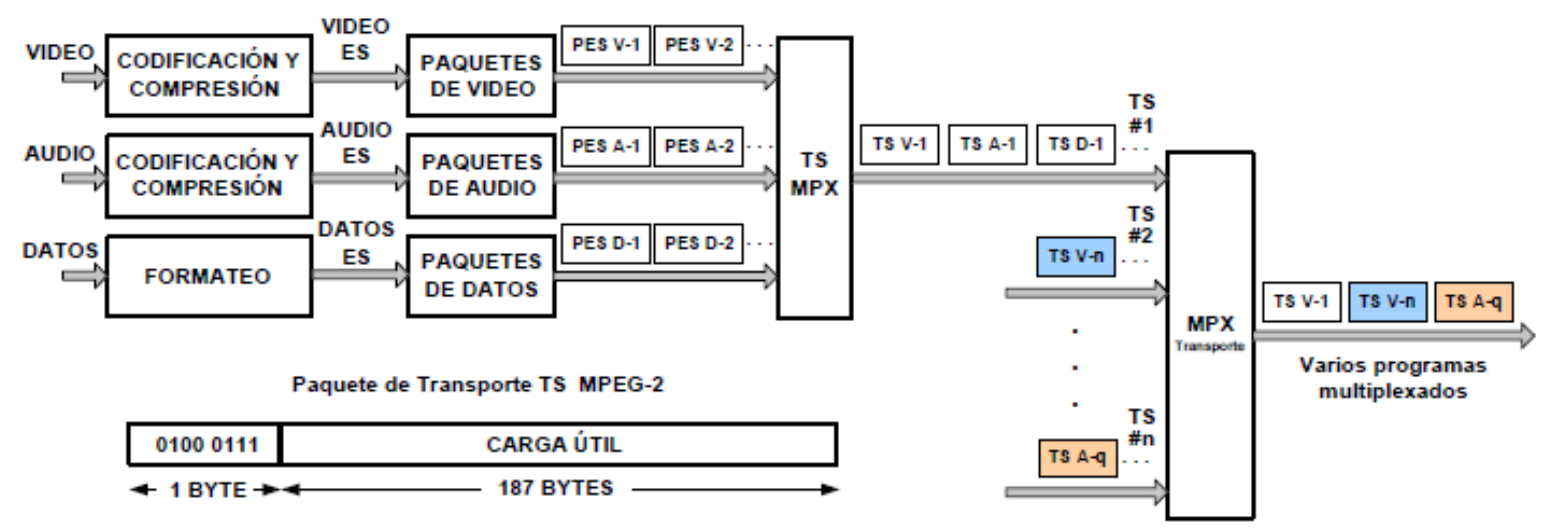

Figura 1.3: Transporte de los paquetes y multiplicación en MPEG-2

En el diagrama de bloques de las Figura 1.3 se puede observar el ingreso de las diferentes señales, estos TS son de audio, video y datos, que al multiplexarse se vuelven un solo flujo de TS los cuales ocupan menos ancho de banda al ser transportados, así se tiene varios programas a la vez del mismo canal.

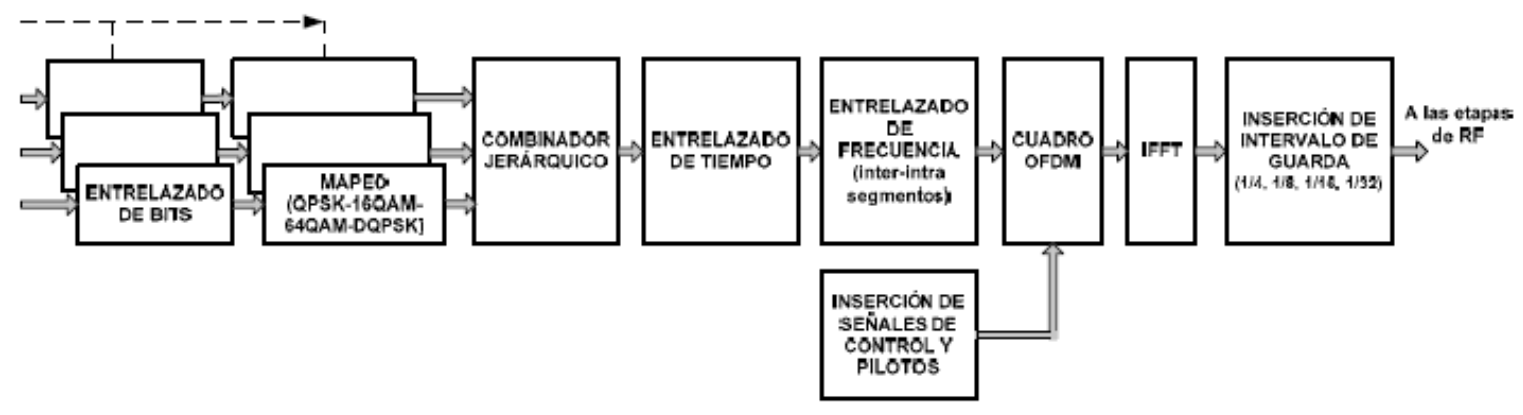

Figura 1.4: Diagrama de bloques de la modulación. 
La medición de la señal a ruido no es efectiva porque no determina de forma directa las condiciones de desempeño de la señal. Para el análisis de desempeño de señales digitales es mejor la tasa de error de modulación (MER) o la magnitud del vector de error (EVM), pero para esta investigación se va a tratar únicamente la tasa de error de modulación.

\section{Tasa de error de modulación (Modulation error ration - MER)}

En la modulación del sistema ISDB-Tb, es donde se puede chequear la tasa de error la cual es un factor que indica la exactitud de una constelación digital que gráficamente es la dispersión de puntos respecto al valor de la señal, cuanto más juntos estén los puntos mejor será la señal como se puede ver en la Figura 1.5. Este proceso sería comparado como la señal a ruido en la modulación análoga.

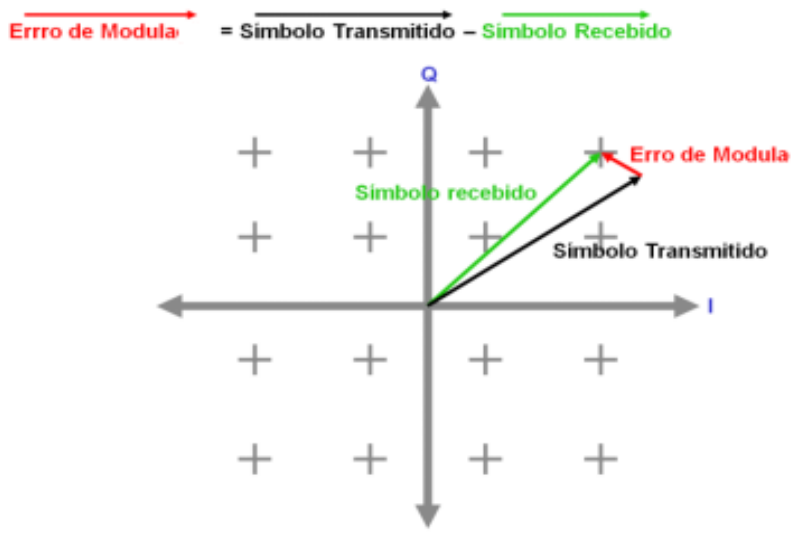

Figura 1.5: Error de la modulación en la constelación.

EI MER es el vector que define el desplazamiento entre los puntos "ideales" en un diagrama de constelación y los reales como se puede ver en la Figura 1.5, es decir, la relación entre la medida de la potencia de la señal DVB y la potencia del "ruido" presente en la constelación. En el MER se incluye todo tipo de deterioro de la señal como ruido, error de fase, error de cuadratura, etc. Se expresa como un valor promedio en $\mathrm{dB}$.
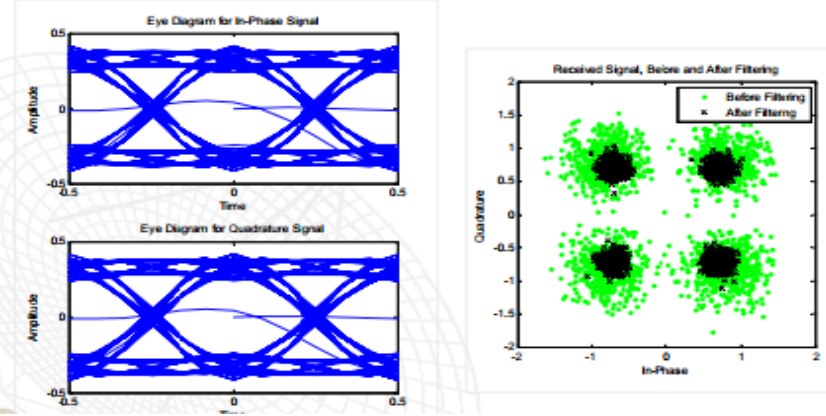

Figura 1.6: Graficas de la señal a ruido y la constelación. 
EI MER permite medir la calidad de la modulación, la relación directa con la cantidad de bits recibidos (BER), el desempeño de la señal, posibles causas de degradación de la señal, distorsiones lineales. También combina los efectos del ruido (CNR), los efectos de no linealidad, retardo de grupo (groupdelay), problemas de respuesta dentro del canal (Ripple y Tilt) y micro reflexiones como se puede ver en la Figura 1.6.

A continuación, se muestra varios ejemplos de las mediciones de los parámetros de calidad de un canal de televisión es el siguiente:

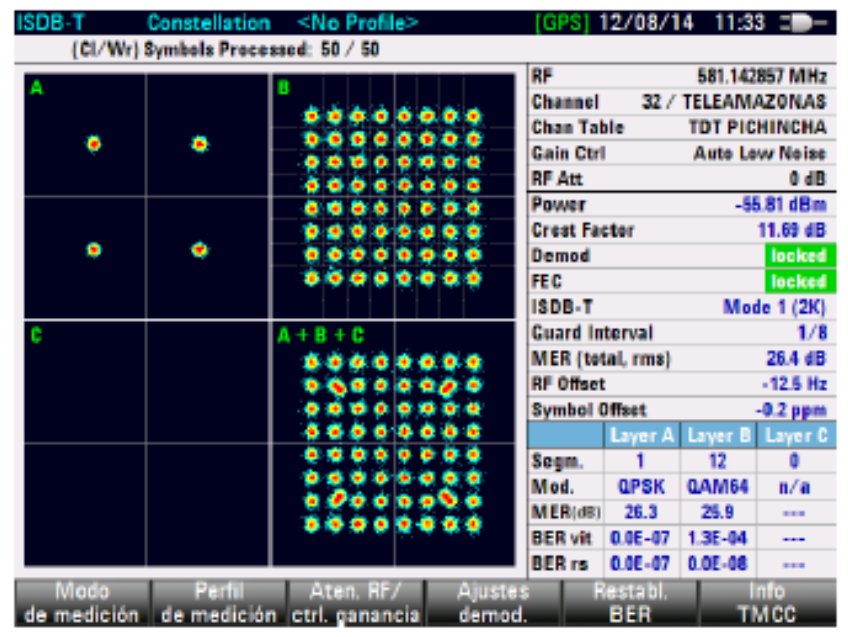

Figura 1.7: Constelación de una señal de televisión óptima.

Como se puede observar en la Figura 1.7, la constelación de puntos es centrada en todos los puntos eso indica que la señal digital que se está revisando es óptima no tiene errores y está en un valor de $26.4 \mathrm{~dB}$ dentro del rango establecido por la Norma ITU del ISDB-Tb.

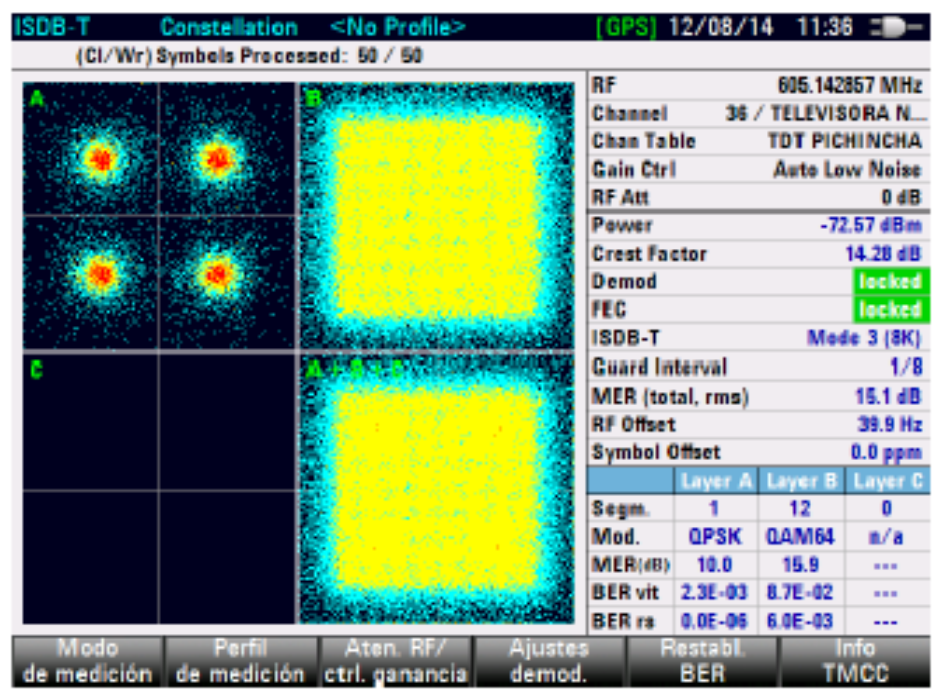

Figura 1.8: Constelación de una señal de televisión con alto ruido. 
En la Figura 1.8 se observa una constelación de puntos totalmente dañada es decir con un alto índice de ruido en la señal digital, esto provoca problemas para el televidente como, por ejemplo: video con líneas y audio con ruido.

El monitoreo la tasa de error de modulación del transmisor digital en la estación terrena del canal, se lo realiza para detectar errores en la calidad de la señal esto se lo logra comparando los valores de las mediciones que se tomaran en la modulación de la señal, antes de transmitirla y en la demodulación de la señal del aire, con esto se tendrá la tasa de error en un rango aceptable para que la calidad de la señal de televisión sea óptima.

En la sección II se describirá los métodos y técnicas que se aplicaron para la realización de la descripción de la señal y para los datos que se recolectaron de las mediciones de la tasa de error de modulación.

En la tercera sección se indicará el diseño de todas las áreas necesarias para generar la señal digital del canal Televicentro y se describe como es la ruta de la señal desde las cámaras hasta la transmisión al aire y su recepción en los usuarios.

En la cuarta etapa se indicará la realización de las mediciones de la tasa de error de modulación en los dos puntos de medición que son: el transmisor digital ubicado en el cerro Pichincha y en la recepción en una residencia de Quito.

\section{MÉTODOS}

El enfoque metodológico que se utiliza para esta investigación fue el mixto, donde se estableció un diálogo entre los paradigmas cuantitativo y cualitativo, con el propósito de poder acceder a toda la información relevante necesaria para el cumplimiento de los objetivos.

También, se utilizó un enfoque analítico porque la investigación se basa en la percepción directa del objeto y del problema. Consiste en el análisis de un objeto se realiza a partir de la relación que existe entre los elementos que conforman dicho objeto como un todo; y a su vez, la síntesis se produce sobre la base de los resultados previos del análisis.

Por otra parte, se utilizará en una primera etapa la observación, tomar información y registrarla para su posterior análisis. La información se recolectará mediante: lista de chequeos de datos, fotografías, escalas, grabaciones.

Otra técnica indispensable es la entrevista, mediante la cual se pudo recopilar de información mediante una conversación profesional, con la que además se adquirió información acerca de lo que se investiga.

Mediante la técnica del fichaje, se registraron los datos que se obtienen al experimental con el objeto de la investigación. Esta técnica se utilizó en la etapa de transmisión y la recepción de la señal en la investigación. 


\section{Diseño}

La estación terrena del canal Televicentro posee toda la infraestructura y los equipos que son necesarios para la generación y transmisión de la señal abierta digital para la ciudad de Quito como se puede observar en la Figura 3.1, la calidad de dicha señal es un punto importante que se debe monitorear y para esto se realiza mediciones y revisiones del transmisor una vez al mes por parte del personal de la Empresa Ecuatronix, los cuales verifican el buen funcionamiento del mismo, pero en esta revisión no se verifica si la señal que se está transmitiendo tiene errores, por esa razón se va a realizar el monitoreo del error de modulación del transmisor y en la demodulación de la recepción de la señal digital.

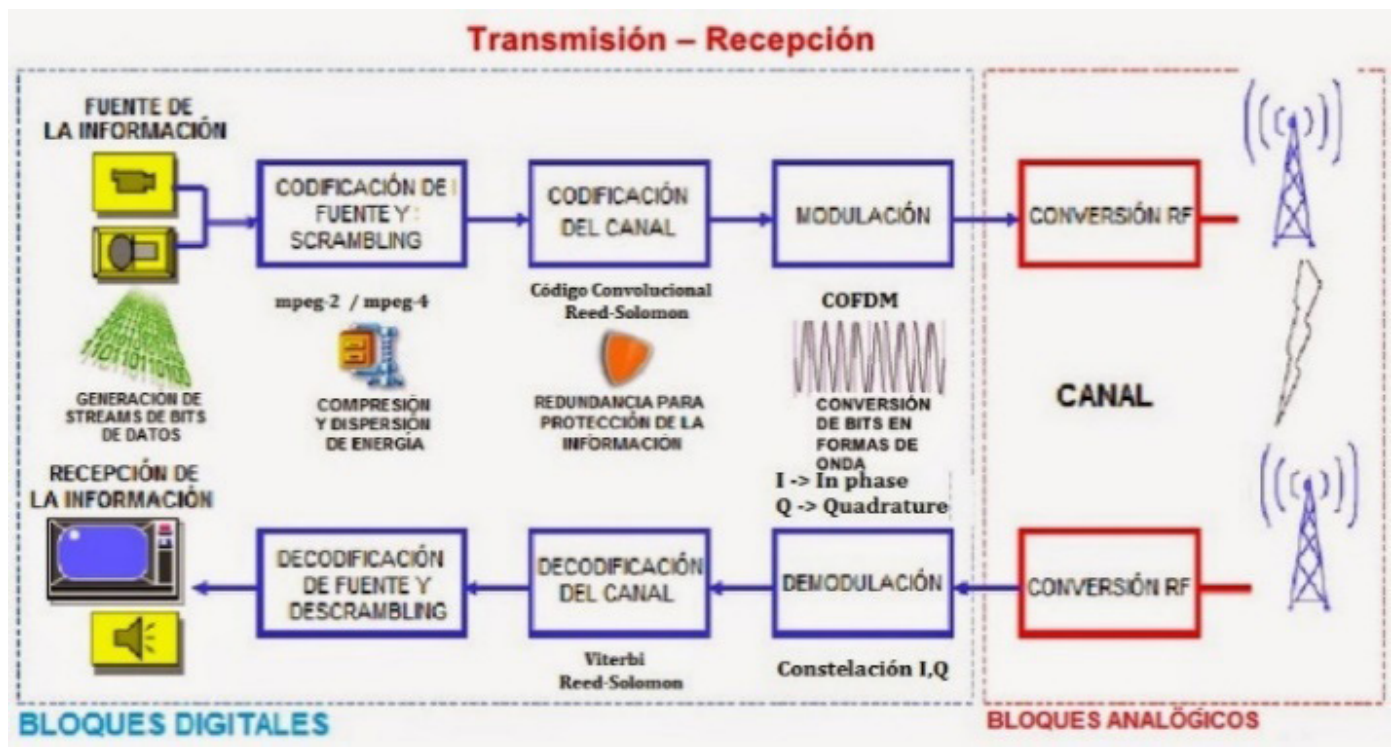

Figura 3.1: Diagrama de bloques de la señal de Televisión.

La señal de televisión en la estación terrena el canal Televicentro para su transmisión proviene de dos fuentes que son: la señal de producción de los programas en vivo y la señal del master de la pauta de programación diaria.

\section{Señal de Producción}

Esta señal consta de dos partes la de video y la de audio. La señal de video de producción como se puede ver en la Figura 3.2 viene del servidor ROSS el cual es un equipo que permite escoger las diferentes fuentes que salen al aire como son:

Las cámaras de los estudios,

- Las notas que realizan los editores que van a los servidores de las notas,

- Los caracteres que aparecen en la parte inferior de la pantalla, 
- El prompter para los presentadores, que son las explicaciones de las notas en las cámaras,

- La microonda que es la transmisión de audio y video en tiempo real,

- El LiveU que es un servidor de transmisión de audio y video en tiempo real,

- La señal de un cable operador para poner cualquier canal nacional e internacional que se necesite.

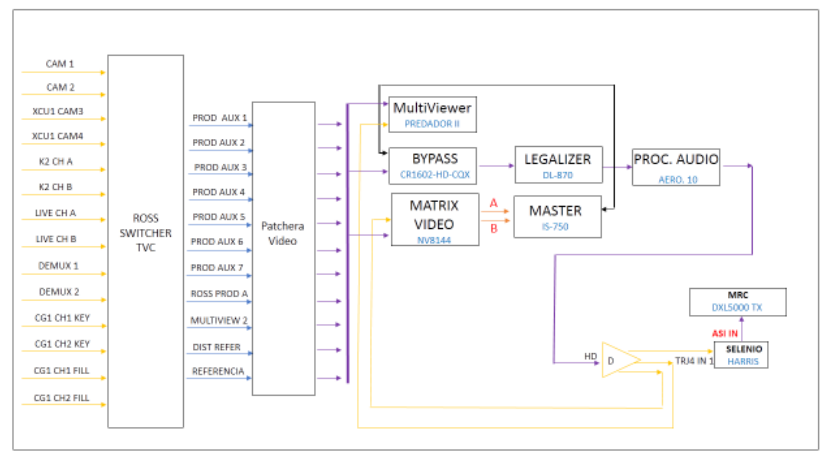

Figura 3.2: Diagrama bloques de la señal de producción.

La señal de audio como se muestra en la Figura 3.3, consta de varias fuentes como en el video que se juntan en la consola de sonido para regular el nivel de sonido que se envía al aire, esta señal pasa a una patchera de audio, a un distribuidor de video y luego al router principal para juntarse con la señal de audio del master del cual se envía las pautas comerciales cuando está en con la programación en vivo o con la programación diaria.

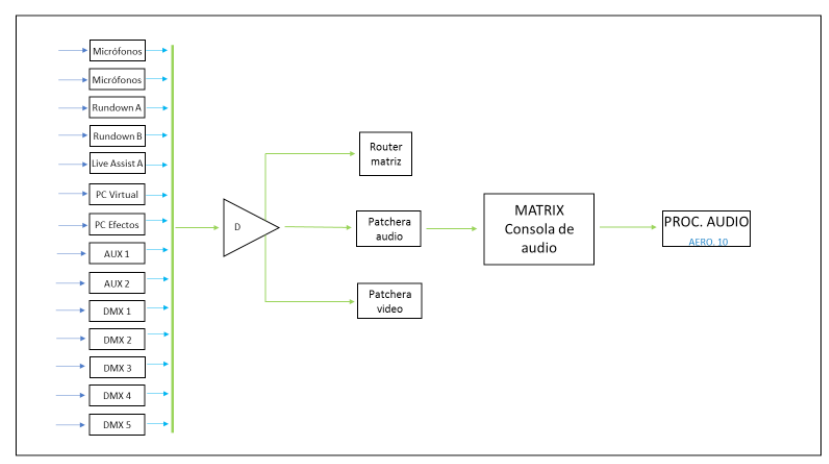

Figura 3.3: Diagrama de bloques de la señal de audio. 


\section{Señal del Master}

La Figura 3.4 muestra la señal del master del canal Televicentro, es donde se rueda la programación de las novelas, los comerciales, las promociones, las películas, las series, etc. que se transmiten en el día.

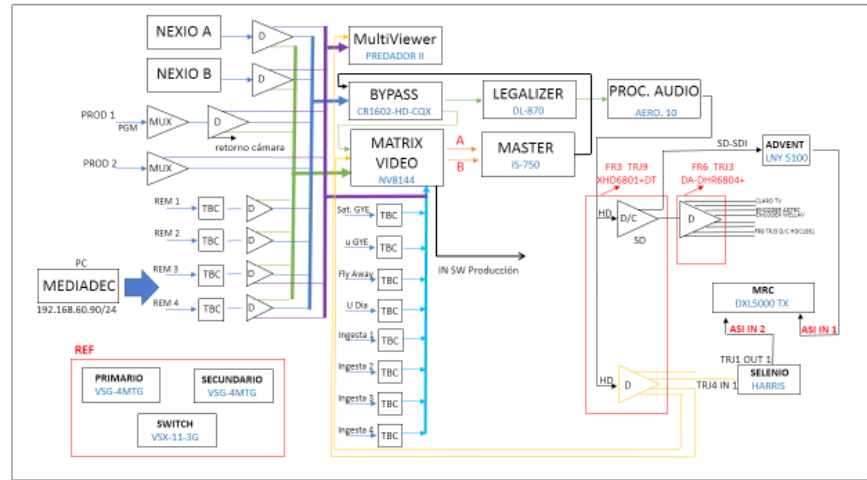

Figura 3.4: Diagrama de bloques del control master.

El recorrido de la señal del master comienza en las editoras de programación donde se dividen en bloques las novelas, series, películas y se mandan a un servidor de contenido en este caso se llama Nexio, este servidor está conectado a un distribuidor de video donde se divide la señal a diferentes equipos los cuales son:

- Multiview que es para monitoreo.

- Servidor de la matriz de video en HD.

- La botonera de ByPass para control del master.

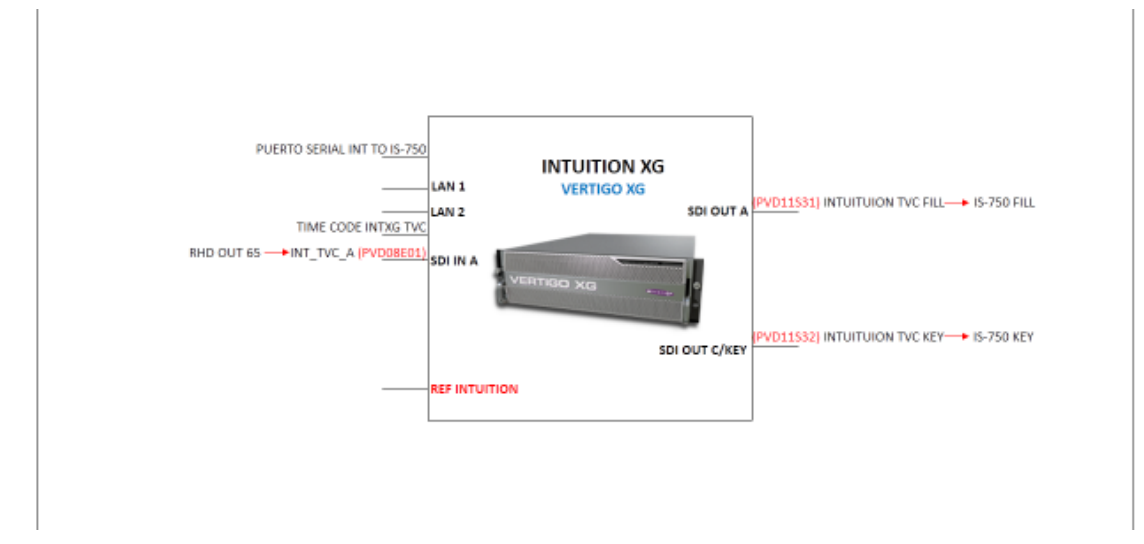

Figura 3.5: Diagrama de entradas y salidas del servidor Intuition. 
La Figura 3.5 muestra al servidor Intuition del Master, es el equipo que permite agregar a la señal de video las sobreimposiciones, clasificaciones, el reloj y el logo que aparece cada cierto tiempo en la programación del canal como se muestra en la Figura 3.6; las sobreimposiciones son imágenes que se imponen a la señal de video como por ejemplo un mensaje para el público; las clasificaciones son el tipo de programa que está apareciendo ese momento como por ejemplo: apto para todo público; el reloj que es la hora del día y por último el logo del canal que aparece en la parte derecha superior de la pantalla como se observa en la Figura 3.7.

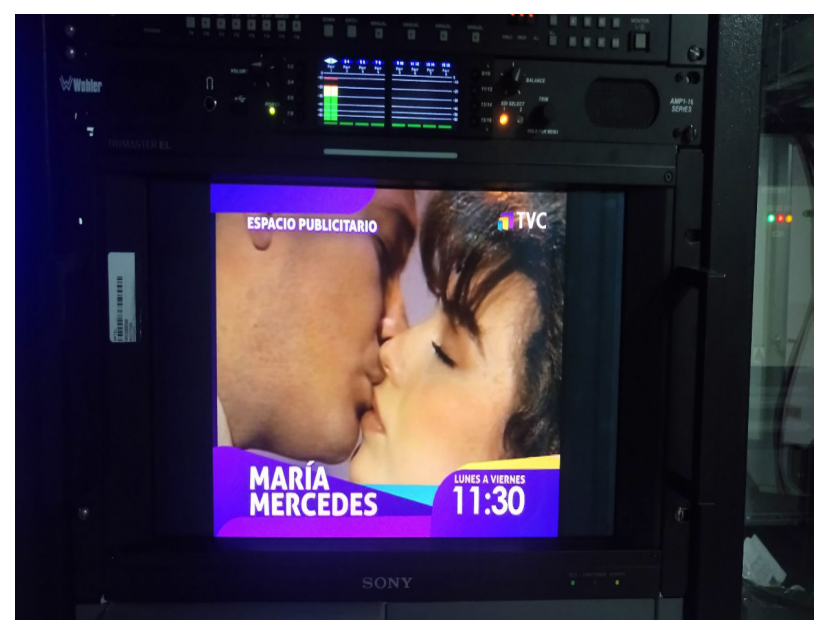

Figura 3.6: Imagen de programación con sobreimposiciones.

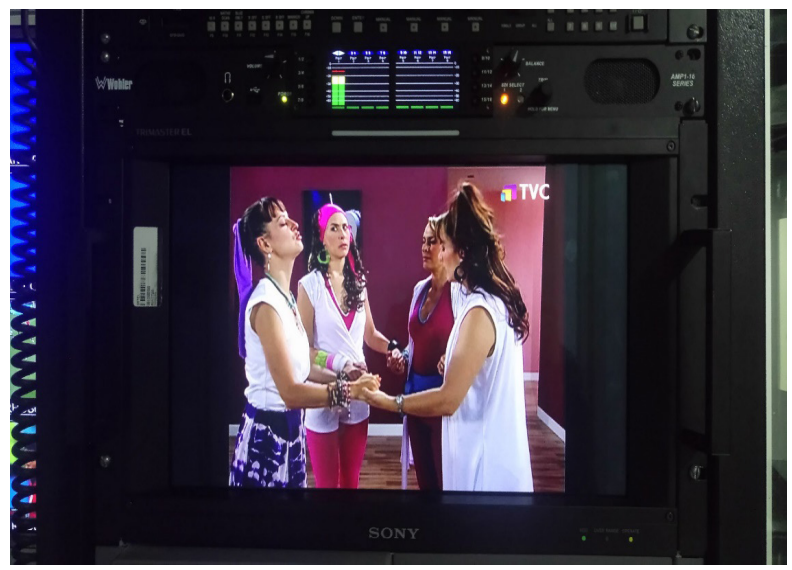

Figura 3.7: Programación del canal con Logo.

La señal del ByPass de la botonera auxiliar pasa al Legalizador de video, es el equipo que nivela los valores CRC, los monitorea y recalcula para garantizar valores de salida adecuados, el estándar para video es $1080-60 i$.

Esta señal pasa al procesador de audio como se puede observar en la Figura 3.8, que es el equipo que nivela los valores de audio impidiendo que el audio se sature o se baje su nivel, el nivel estándar de audio es -20 LKFS. 


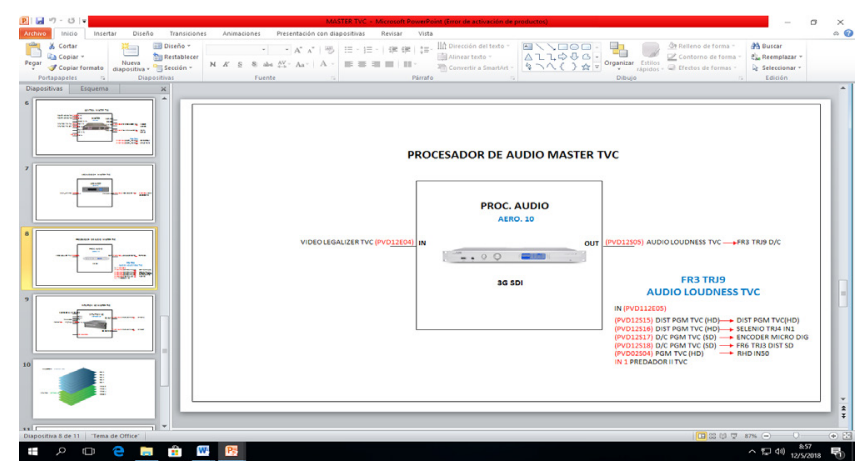

Figura 3.8: Diagrama en bloque del procesador de audio

Toda la señal es embebida que quiere decir audio y video por el mismo canal y en formato HD que quiere decir alta definición (High Definition).

Por último, la señal se pasa por un equipo llamado Selenio que permite convertir a los parámetros en HD necesarios para su transmisión desde la microonda. El equipo Selenio realiza la conversión de parámetros para TDT que significa Televisión Digital Terrestre, el parámetro de video debe estar en ASI y el de audio en AACL2.

Una vez lista la señal con los parámetros de audio y video para HD se envía a la microonda de transmisión que es un equipo MRC DXL5000, en la estación terrena.

\section{Implementación}

\section{Transmisión de la señal al aire}

La transmisión de la señal al aire, se la realiza en el Cerro Pichincha, donde se encuentran los equipos encargados de tomar la señal embebida en video y audio para que los receptores de televisión digital capten la señal, como se puede observar en la Figura 3.9.

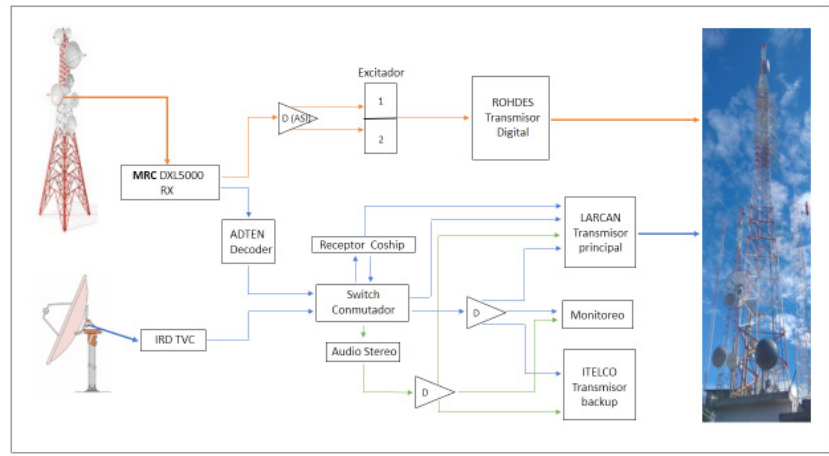

Figura 3.9: Diagrama de bloques de la recepción de la señal. 
La transmisión empieza mediante un enlace de microonda en el Cerro Pichincha con el receptor MRC DXL5000 como se muestra en la Figura 3.10 que se tiene en la caseta, este receptor posee dos salidas: la una para la señal digital y la otra para la señal análoga, pero esta señal no se necesita para la investigación.

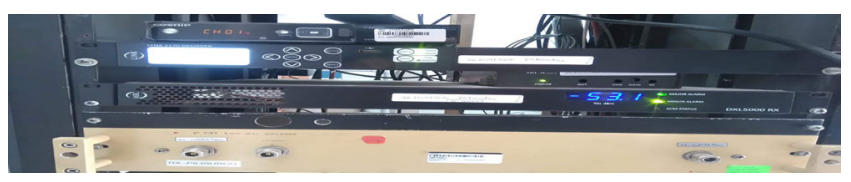

Figura 3.10: Receptor digital de la señal de televisión en el cerro Pichincha.

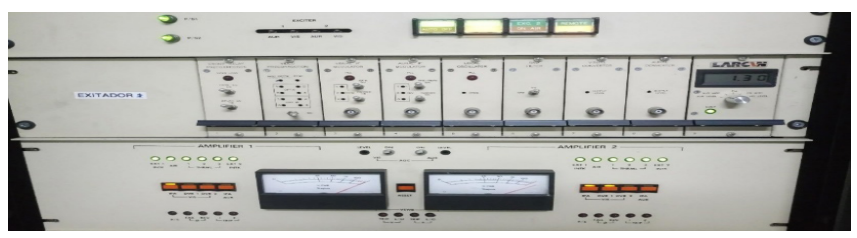

Figura 3.11: Imagen del excitador que se encuentra en el cerro Pichincha.

La salida que se va a utilizar para la transmisión digital se la envía a un distribuidor, que permite tener dos salidas a los excitadores en redundancia indicado en la Figura 3.11 que posee el transmisor ROHDES, esta señal pasa por un filtro para atenuar las ondas de los armónicos como se puede ver en las Figuras 3.12 y 3.13, y llegar a tener una señal limpia la cual se enviará a las antenas, llegando la señal a los ciudadanos mediante ondas de radiofrecuencia que captan los dispositivos para televisión digital.

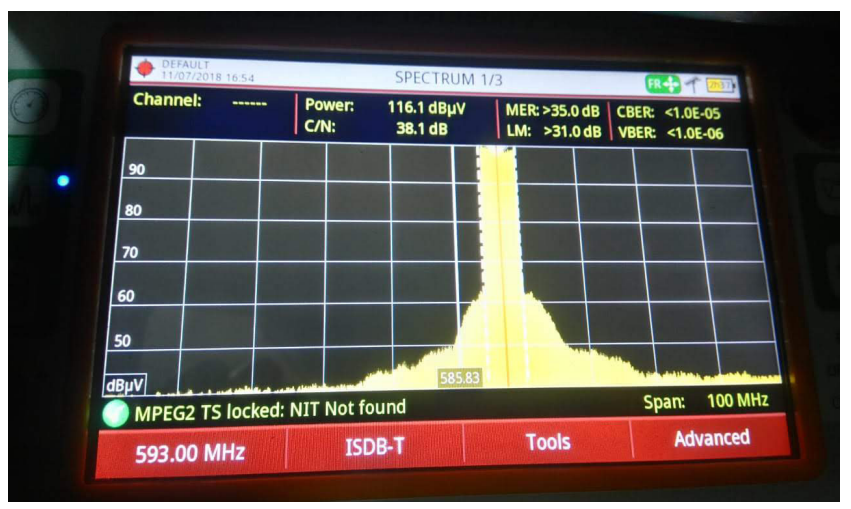

Figura 3.12: Señal digital en el transmisor antes del filtro. 


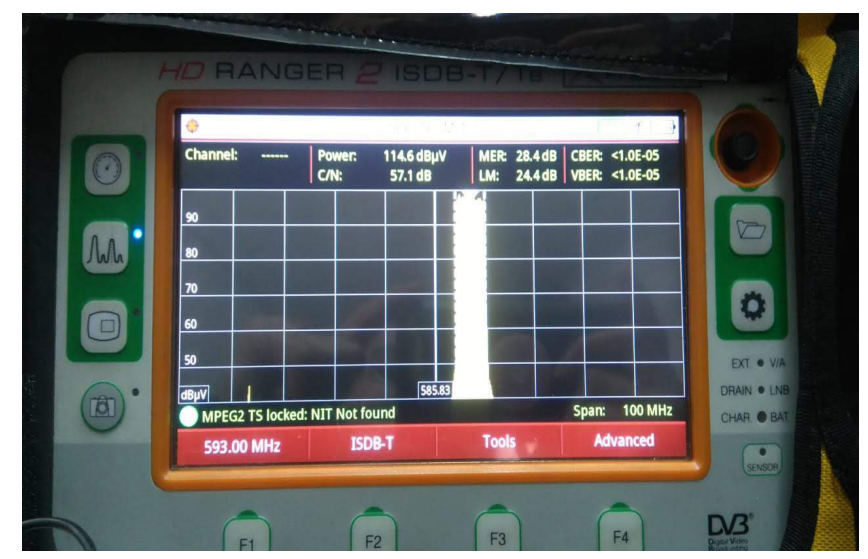

Figura 3.13: Señal digital en el transmisor después del filtro.

La demodulación de la señal digital como se muestra en la Figura 3.14, va a depender de la manera que se desee sintonizar la señal y del aparato que tenga el ciudadano, existen varias opciones como las siguientes:

- La primera opción es si el televisor es análogo, pero se puede poner un aparato externo para que pueda sintonizar la señal digital.

- La segunda opción es que el televisor sintonice la señal digital directamente del aire.

- La tercera opción es si posee un receptor móvil como del automóvil.

- La cuarta opción es si se desea sintonizar con dispositivos portátiles como el celular o un watchman. 


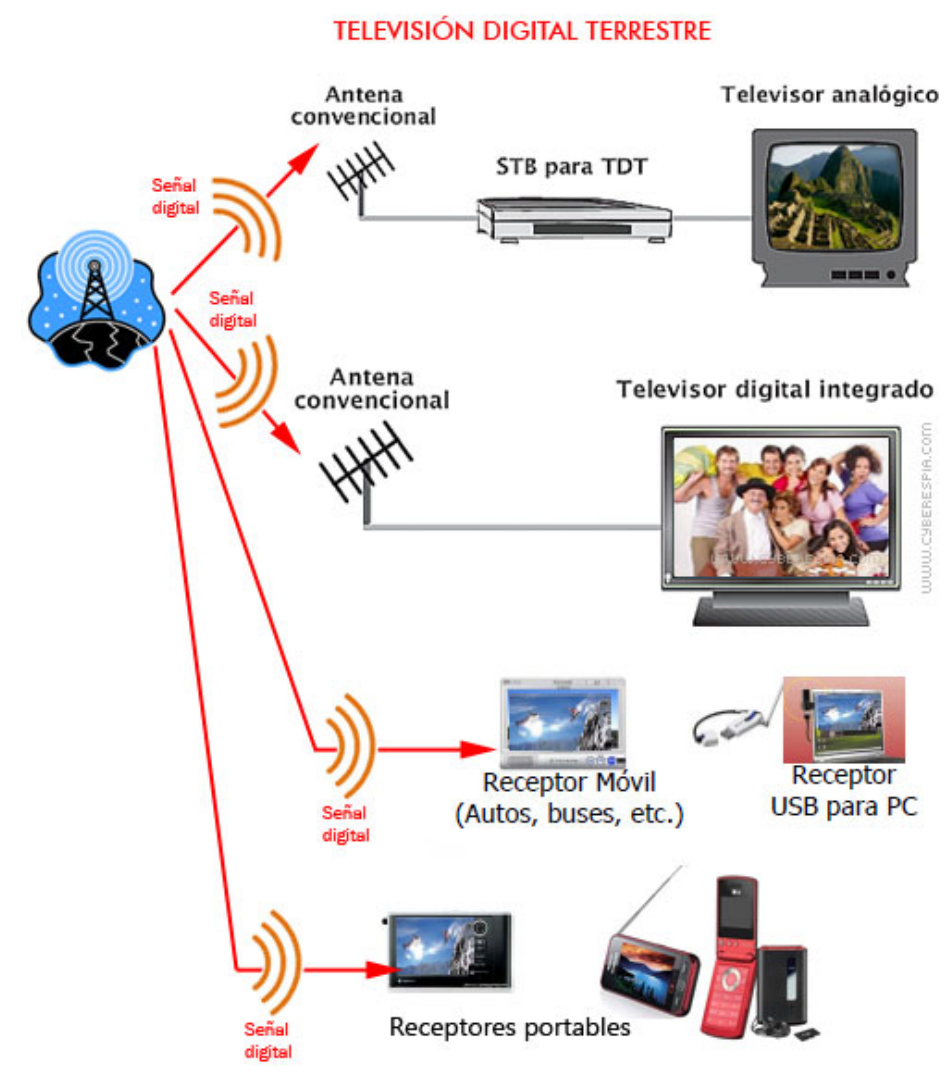

Figura 3.14: Esquema de la recepción de la señal digital.

\section{Procesamiento de la información}

Los datos que se tiene son los valores de las mediciones del error de modulación en la transmisión digital de la señal y en la demodulación de la recepción de la señal del aire, os cuales ayudara a chequear la calidad de la señal que se está transmitiendo a los ciudadanos.

Estos datos se obtienen de las mediciones en dos puntos específicos los cuales son: antes de transmisor en la estación terrena y al receptar la señal y demodular mediante una antena dipolo o casera.

El primer punto de medición del error de modulación se lo realiza antes del transmisor digital que se encuentra en el Cerro Pichincha, como se puede ver en la Figura 3.15, que es el equipo que convierte la señal de video en ASI y la señal de audio en AAC, parámetros necesarios para la señal digital, antes de que ingrese al transmisor digital. 


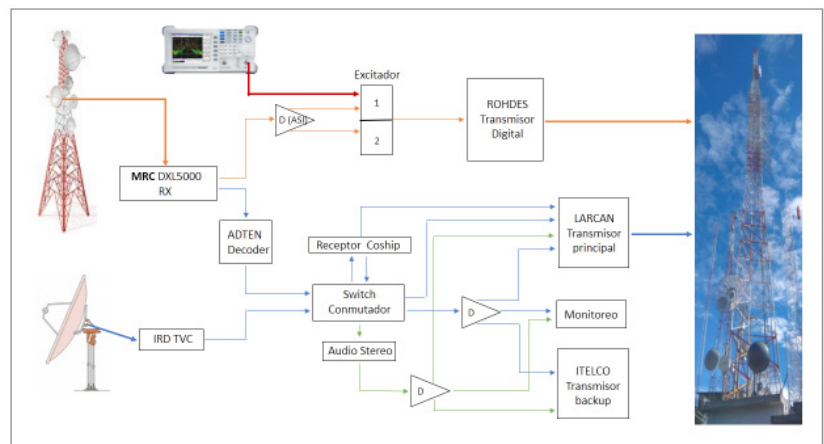

Figura 3.15: Primer punto de medición del error de modulación.

En la Figura 3.16, se puede observar la toma de mediciones mediante un analizador de espectros que mida señales terrestres y poniendo la frecuencia del canal digital que está en el rango $591 \mathrm{MHz}$ a $595 \mathrm{MHz}$, una vez que se engancha la señal se pueden ver varios valores, pero el que se necesita es el MER y está en un valor de $35 \mathrm{~dB}$ que es óptimo para la transmisión de la señal al aire.

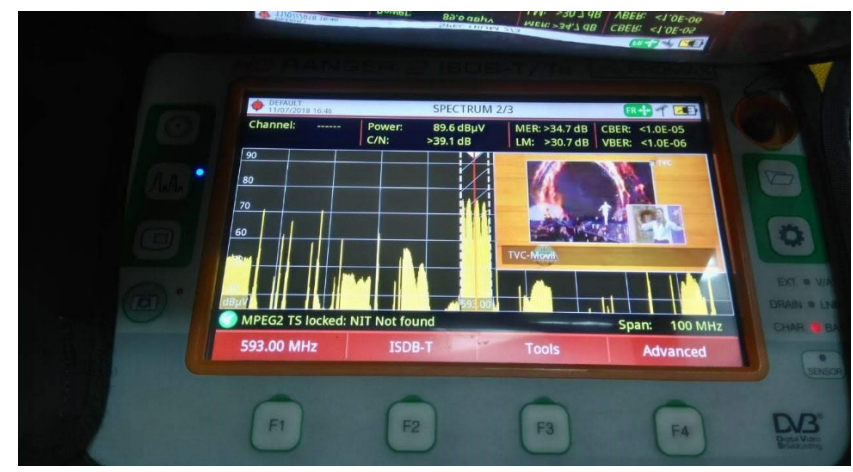

Figura 3.16: Imagen de la toma de mediciones del transmisor.

Los datos realizados del MER en el transmisor se los realizo por 50 días consecutivos como se puede observar en la Tabla 3.1, los datos que se obtuvieron son antes del filtro y después del filtro del transmisor, se obtuvo el valor promedio de $34.921 \mathrm{~dB}$ mediante la fórmula 1, si la respuesta se redondea queda en $35 \mathrm{~dB}$, estando en un rango óptimo de transmisión teniendo un valor estable de MER, como se puede observar en la figura 3.16.

$$
M(x)=\frac{\sum_{i}^{\mathrm{E}} X i * n i}{N}
$$

Fórmula 3.1: Fórmula del promedio o la media aritmética.

$$
M(x)=\frac{1746.1 \mathrm{~dB}}{50}=34.921 \mathrm{~dB}=35 \mathrm{~dB}
$$


Los datos realizados en el transmisor son los siguientes:

\begin{tabular}{|c|c|c|}
\hline & lediciones & \\
\hline Nro. & Antes filtro & Después filtro \\
\hline 1 & 34.7 & 34.7 \\
\hline 2 & 34.9 & 34.9 \\
\hline 3 & 35.0 & 35.0 \\
\hline 4 & 35.0 & 35.0 \\
\hline 5 & 35.0 & 35.0 \\
\hline 6 & 34.9 & 34.9 \\
\hline 7 & 34.9 & 34.9 \\
\hline 8 & 34.9 & 34.9 \\
\hline 9 & 34.9 & 35.0 \\
\hline 10 & 34.7 & 34.7 \\
\hline 11 & 34.7 & 34.7 \\
\hline 12 & 34.7 & 34.9 \\
\hline 13 & 34.9 & 34.9 \\
\hline 14 & 34.9 & 34.9 \\
\hline 15 & 34.9 & 35.0 \\
\hline 16 & 35.0 & 35.0 \\
\hline 17 & 35.0 & 35.0 \\
\hline 18 & 35.0 & 35.0 \\
\hline 19 & 35.0 & 35.0 \\
\hline 20 & 35.0 & 34.9 \\
\hline 21 & 34.9 & 35.0 \\
\hline 22 & 34.9 & 35.0 \\
\hline 23 & 35.0 & 34.9 \\
\hline 24 & 34.9 & 34.9 \\
\hline 25 & 34.9 & 35.0 \\
\hline 26 & 35.0 & 35.0 \\
\hline 27 & 35.0 & 35.0 \\
\hline 28 & 35.0 & 35.0 \\
\hline 29 & 35.0 & 34.9 \\
\hline 30 & 34.9 & 34.9 \\
\hline 31 & 34.9 & 34.9 \\
\hline 32 & 34.9 & 34.7 \\
\hline 33 & 34.7 & 34.7 \\
\hline 34 & 34.7 & 34.9 \\
\hline 35 & 34.9 & 34.9 \\
\hline 36 & 34.9 & 35.0 \\
\hline
\end{tabular}




\begin{tabular}{lll}
\hline 37 & 35.0 & 35.0 \\
\hline 38 & 35.0 & 35.0 \\
\hline 39 & 35.0 & 35.0 \\
\hline 40 & 35.0 & 35.0 \\
\hline 41 & 35.0 & 34.9 \\
\hline 42 & 34.9 & 34.9 \\
\hline 43 & 34.9 & 34.7 \\
\hline 44 & 34.7 & 34.9 \\
\hline 46 & 34.9 & 34.9 \\
\hline 47 & 34.9 & 35.0 \\
\hline 48 & 35.0 & 35.0 \\
\hline 50 & 35.0 & 35.0 \\
\hline
\end{tabular}

Tabla 3.1: Datos medición del MER en el transmisor de microonda.

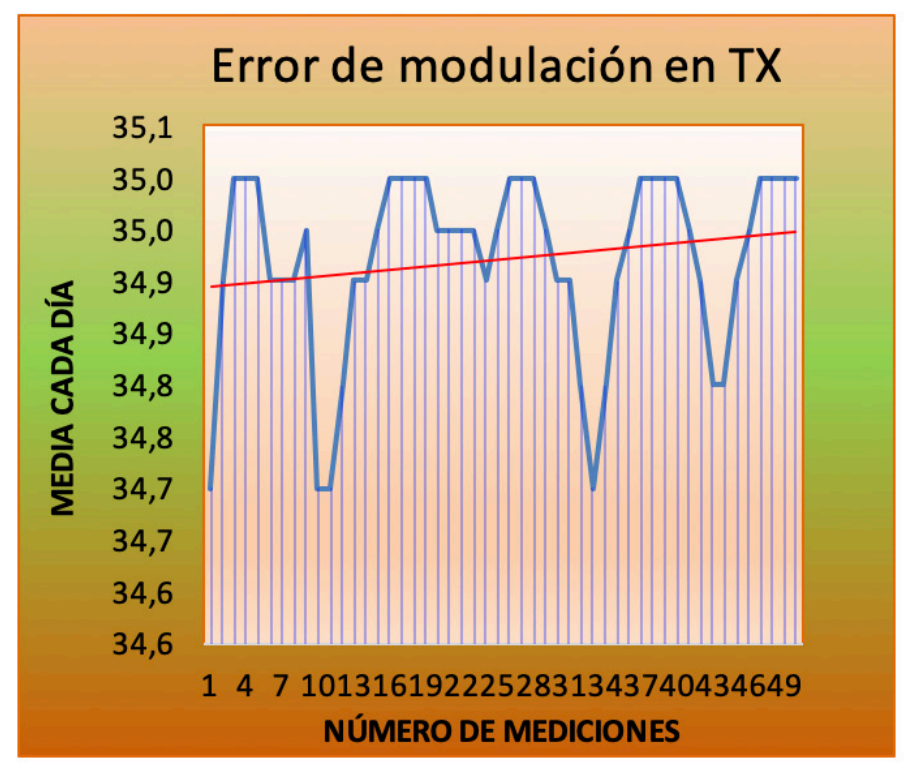

Figura 3.17: Histograma de las medias del MER en el transmisor.

El segundo punto de medición del error de modulación se lo realiza en la recepción la señal digital como se puede ver en la Figura 3.17, esto es mediante una antena digital o cualquier antena casera para obtener los valores de MER que deben estar por encima de $23 \mathrm{~dB}$ en la antena y por encima de $21 \mathrm{~dB}$ en las tomas, el valor óptimo es de $40 \mathrm{~dB}$. 


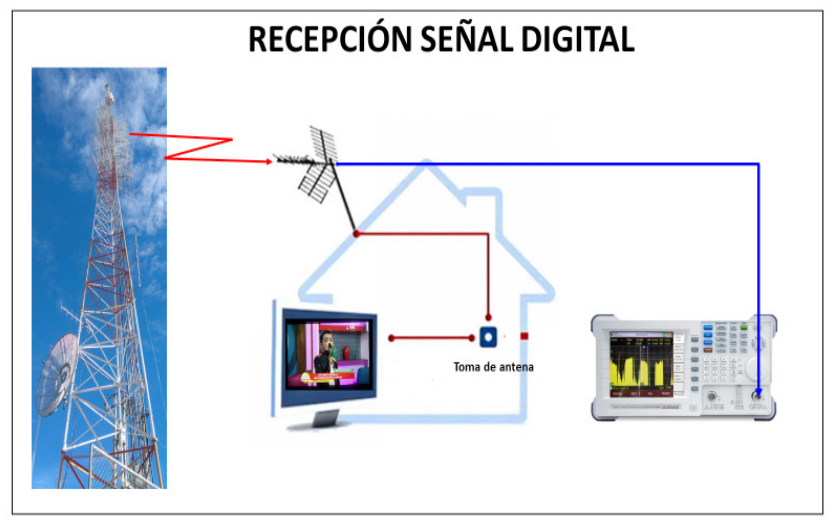

Figura 3.18: Segundo punto de medición del error de modulación.

Los datos realizados de la demodulación de la señal se lo realizo en dos sitios de la ciudad, los cuales son: el canal Televicentro y una residencia.

\section{Canal Televicentro}

\begin{tabular}{lcc}
\hline \multicolumn{3}{l}{ Oficina del Canal Televicentro } \\
\hline Fecha & Nro. & Mediciones del MER \\
\hline & 1 & 33.0 \\
\cline { 2 - 3 } $25 / 05 / 2018$ & 2 & 33.4 \\
\cline { 2 - 3 } & 3 & 33.7 \\
\cline { 2 - 3 } & 4 & 34.0 \\
\hline \multirow{3}{*}{$01 / 06 / 2018$} & 1 & 31.6 \\
\cline { 2 - 3 } & 2 & 32.8 \\
\hline & 3 & 33.0 \\
\hline \multirow{3}{*}{$08 / 06 / 2018$} & 4 & 33.4 \\
\cline { 2 - 3 } & 2 & 32.6 \\
\cline { 2 - 3 } & 3 & 32.8 \\
\hline
\end{tabular}

Tabla 3.2: Datos medición del MER en el canal Televicentro.

En la Figura 3.19 se observa la obtención de las mediciones de la recepción de la señal con una antena digital, en los datos de la Tabla 3.2 se puede observar que el valor varía en un rango de $0.02 \mathrm{~dB}$ y $0.03 \mathrm{~dB}$, pero siempre se encuentra sobre los $23 \mathrm{~dB}$ en el valor de MER, para obtener una calidad óptima en audio y video. 


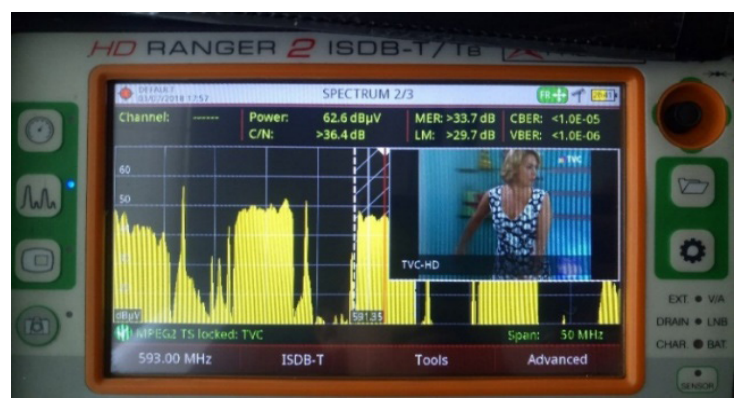

Figura 3.19: Imagen de la toma de mediciones en el canal Televicentro.

En la Figura 3.20 se puede observar la toma de mediciones con una antena digital en la oficina del canal Televicentro.

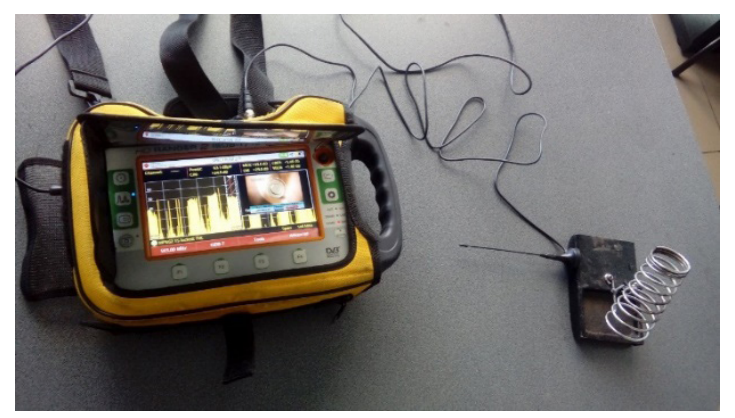

Figura 3.20: Mediciones del MER canal Televicentro.

Residencia en Quito

\begin{tabular}{|c|c|c|}
\hline Residencia & & \\
\hline Fecha & Nro. & Mediciones del MER \\
\hline \multirow{4}{*}{$28 / 05 / 2018$} & 1 & 29.0 \\
\hline & 2 & 29.2 \\
\hline & 3 & 29.5 \\
\hline & 4 & 30.0 \\
\hline \multirow{4}{*}{ 04/06/2018 } & 1 & 31.7 \\
\hline & 2 & 31.9 \\
\hline & 3 & 32.0 \\
\hline & 4 & 32.3 \\
\hline \multirow{4}{*}{$11 / 06 / 2018$} & 1 & 30.0 \\
\hline & 2 & 31.3 \\
\hline & 3 & 31.5 \\
\hline & 4 & 31.7 \\
\hline
\end{tabular}

Tabla 3.3: Datos medición del MER en una residencia. 
En la Figura 3.21 se observa la obtención de las mediciones de la recepción de la señal con una antena casera en una residencia en la ciudad de Quito, de dichas mediciones de la Tabla 3.3 se puede observar que los valores están entre $29 \mathrm{~dB}$ a $31 \mathrm{~dB}$ en la recepción, siendo un valor óptimo de calidad, estos valores también se encuentran sobre los $23 \mathrm{~dB}$ en el valor de MER.

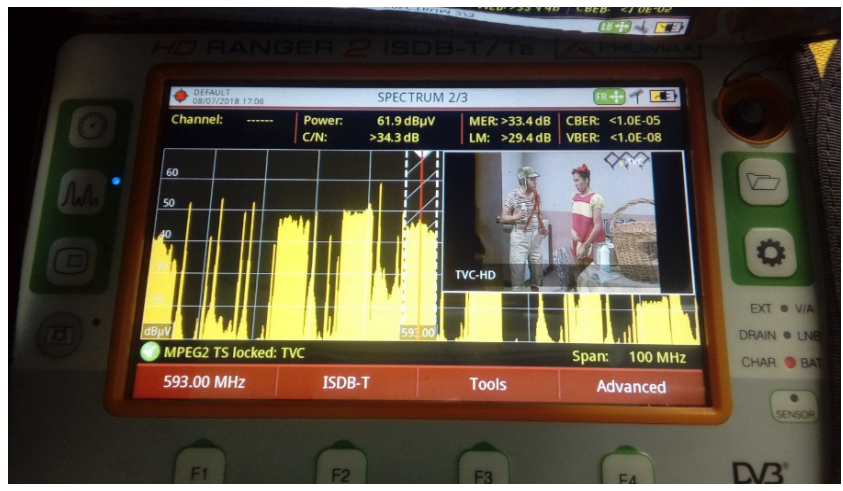

Figura 3.21: Imagen de la toma de mediciones en una residencia.

Las mediciones se las realizó mediante una antena digital como se puede ver en la Figura 3.22 y una antena casera en este caso una Yagi como se puede ver en la Figura 3.23, los valores del MER obtenidos en el campo varían entre $29 \mathrm{~dB}$ y $33 \mathrm{~dB}$, este valor es mayor a los $23 \mathrm{~dB}$ que se debe superar en la medición de la antena, para tener una buena recepción de la señal y una calidad óptima en audio y video.

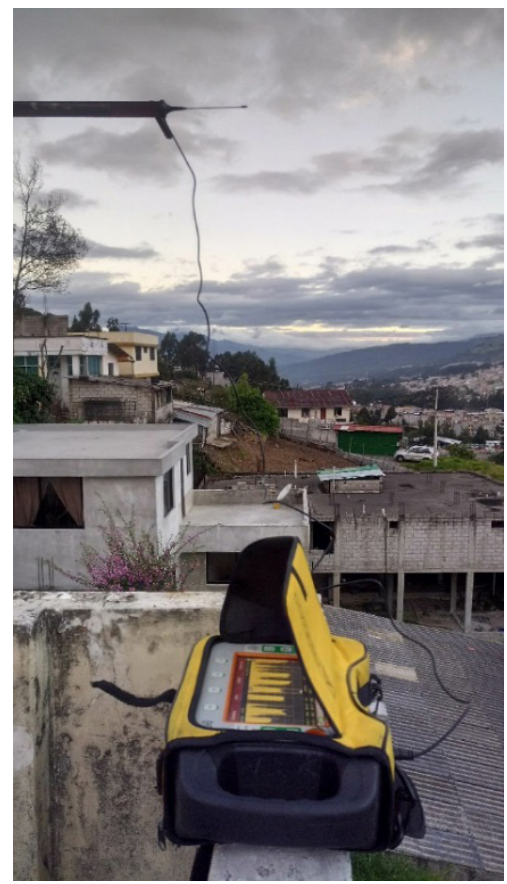

Figura 3.22: Mediciones del MER con una antena digital. 


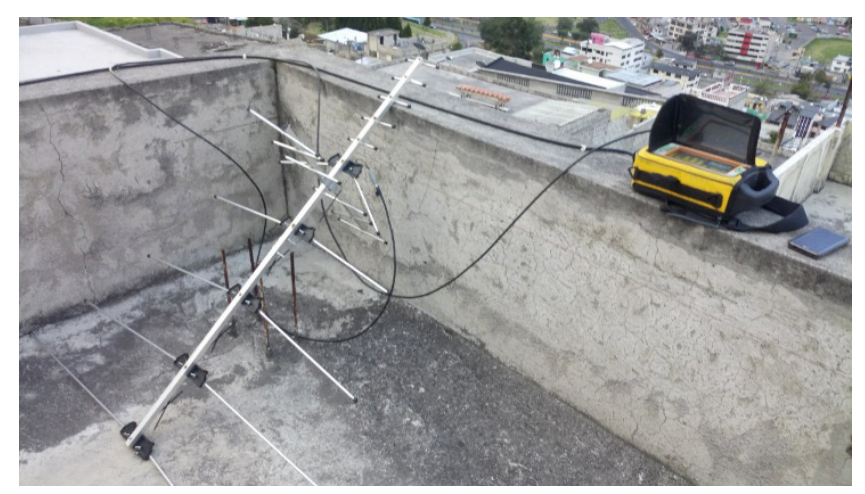

Figura 3.23: Mediciones del MER con una antena casera.

En todas las mediciones del MER de la señal digital que se realizó tanto en la transmisión como en la recepción, se obtuvo un diagrama de constelación con todos los puntos centrados en los cuatro cuadrantes dando como evidencia que la señal es óptima y no posee ningún tipo de error como se puede observar en la Figura 3.24.

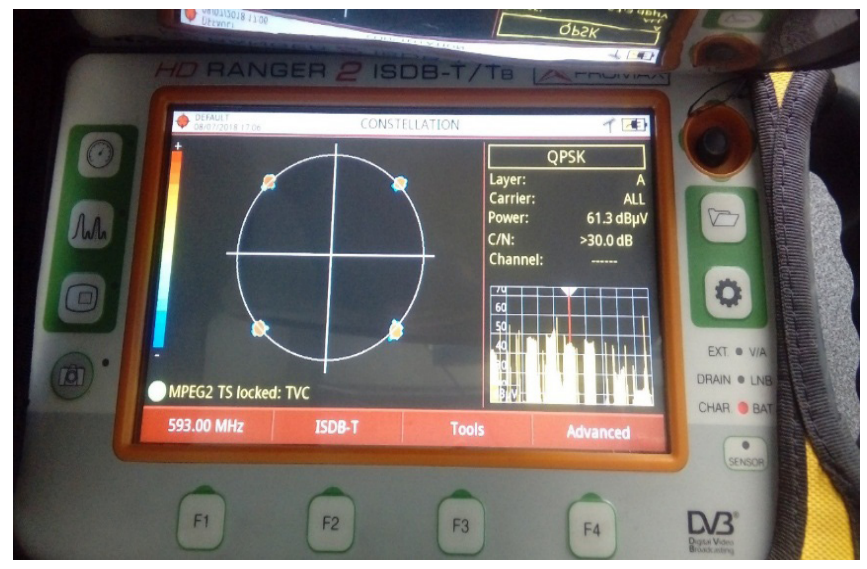

Figura 3.24: Diagrama de constelación de la señal digital.

\section{Generación de la señal}

El canal Televicentro posee el estándar ISDB-T Internacional para la televisión digital terrestre que se implementara en los siguientes años de acuerdo a la Norma Técnica para el servicio de Radiodifusión de Televisión Digital Terrestre de la resolución ARCOTEL-2015-0301. La generación de la señal del canal posee el formato de alta definición en 1080i con relación de aspecto 16:9.

\section{Transmisión de la señal}

Los datos realizados del MER en el transmisor se los realizo por 50 días consecutivos, los datos que se obtuvieron son antes del filtro y después del filtro del transmisor, se obtuvo el valor 
promedio de $34.921 \mathrm{~dB}$, redondeando queda en $35 \mathrm{~dB}$, estando en un rango óptimo de transmisión teniendo un valor estable de MER.

\section{Recepción de la señal}

Las mediciones de la recepción de la señal con una antena digital, se puede observar que el valor varía en un rango de $0.02 \mathrm{~dB}$ y $0.03 \mathrm{~dB}$, pero siempre se encuentra sobre los $23 \mathrm{~dB}$ en el valor de MER, para obtener una calidad óptima en audio y video.

Las mediciones de la recepción de la señal con una antena casera en una residencia en la ciudad de Quito, se puede observar que los valores están entre 29dB a 31dB en la recepción, siendo un valor óptimo de calidad, estos valores también se encuentran sobre los $23 \mathrm{~dB}$ en el valor de MER.

\section{RESULTADOS Y CONCLUSIONES}

El canal de televisión Televicentro posee toda la infraestructura y los equipos necesarios para la generación y transmisión de la señal digital, una vez que entre en vigencia en el país; la generación de la señal es en alta definición y embebida, es decir audio y video en un solo canal de transmisión.

La tasa de error de modulación es el parámetro que cuantifica los errores de una constelación digital, este factor facilita valorar si una señal digital es buena. El cálculo de este factor en transmisión, lleva implícita la demodulación de la señal para la evaluación. En recepción, este parámetro se determina tras la demodulación propia de la recepción de los datos. En ambos casos, es necesario el uso de la constelación de transmisión normalizada como referencia.

Los dos puntos de evaluación de la tasa de error de modulación que salieron de los resultados del análisis de la generación de la señal fueron: en el transmisor digital y en la recepción al demodular la señal digital. Estas mediciones ayudan a determinar la ganancia de la antena que se usa para la recepción de la señal digital.

La calidad de la señal que se transmite en la estación terrena del canal Televicentro tuvo un valor promedio de $36.554 \mathrm{~dB}$ y de $34.38 \mathrm{~dB}$ en la recepción de la señal digital, respecto al valor mínimo que se debe superar en este caso de $23 \mathrm{~dB}$ y llegando a un valor óptimo de $40 \mathrm{~dB}$. 


\section{REFERENCIAS BIBLIOGRÁFICAS}

CreativeCommons. (2011). Opiniones de Televisión digital terrestre. Obtenido de DatuOpinion.com : http://www. datuopinion.com/television-digital-terrestre

González Morales, A., Gallardo López, T., \& Del Pozo Sánchez, F. (2016). Metodología de la Investigación. Quito: Jurídica del Ecuador.

Hernández, P., \& Poltoski, G. (2003). ¿ Ser digital? El dilema de la televisión digital terrestre en América Latina. Obtenido de https://cedoc.infd.edu.ar/upload/Glenn_Polstolski.pdf

M, J. (09 de 02 de 2013). Obtenido de Medir la señal DVB-T / Analizador Transport Stream (DVB-T): http://tdtdvb-t.blogspot.com/

Oliveros, H., \& Ferrari, H. (2012). Televisión Digital Terrestre - Norma ISDB-Tb. Obtenido de http://www.edutecne.utn.edu.ar: http://www.edutecne.utn.edu.ar/cytal_frvm/CyTAL_2012/TF/TF013.pdf

Pisciotta, N. O. (2010). Sistema ISDB-Tb. En Sistema ISDB-Tb (págs. 4-30). Centro de Investigación Aplicada y Desarrollo en Informatica y Telecomunicaciones (CLADE-IT).

Telecomunicaciones, M. d. (05 de Mayo de 2018). Ministerio de Telecomunicaciones. Obtenido de https://tdtecuador.mintel.gob.ec/contexto-internacional/

Tomasi, W. (2003). Sistemas de Comunicaciones Electrónicas. En W. Tomasi, Sistemas de Comunicaciones Electrónicas (págs. 5, 6). Mexico: Pearson Educación .

Universo fórmulas. (2017). Obtenido de Universo fórmulas: http://www.universoformulas.com/estadistica/descriptiva/media/

Vásquez, X. S. (2015). Medición de parámetros de calidad de las señales de televisión digital terrestre (tdt) en sitios identificados como zonas de sombra dentro del distrito metropolitano de quito. Obtenido de Revista Politécnica: https://www.revistapolitecnica.epn.edu.ec/ojs2/index.php/revista_politecnica2/article/ view/363 